\title{
Sleep and sleepiness in relation to pain in pediatric surgery patients - an exploratory pilot study
}

\author{
Lukas J Rulfs ${ }^{1 *}$, Brigitte Messerer ${ }^{2},{\text { Alexander Avian}{ }^{1}, \text { Andrea Berghold }}^{1}$ \\ From Safety in hospitals: from strategy to implementation Annual Scientific Meeting 2015 \\ Graz, Austria. 29-30 September 2015
}

\section{Background}

Recent studies suggest a reciprocal relationship between pain and sleeping disorders among adult patients [1] and different biological mechanisms are being proposed $[2,3]$. Data with regard to this topic is very limited in pediatric patients. The present study aims to serve as an exploratory pilot study regarding the relationship between pain and sleep in children and adolescents.

\section{Materials and methods}

Choosing a combined qualitative and quantitative method we interviewed 40 postoperative children and adolescents (age 11-18) at the Department of pediatric and adolescent surgery of the Medical University of Graz regarding their sleep, sleepiness and pain in semi-structured interviews. For contextual data the patient charts were analysed retrospectively.

\section{Results}

Thirty eight (95\%) patients reported suffering from disturbed sleep in the hospital. Out of all patients, 23 (58\%) had problems falling asleep because of pain, 20 (50\%) woke up during the night because of pain and 38 (95\%) indicated tiredness during the day.

Higher maximal pain during the preceding 36 hours and the occurrence of pain in the night before the questioning took place was related to worse sleep quality as well as to higher sleepiness at the time of interview. Current sleepiness and a general sleepiness during the day were associated with a higher subjective pain level. The same results could be found in case of lower sleep quality during the whole stay in the hospital and in case of sleep disturbance in the night before the questioning took place.

\section{Conclusions}

Recovery after a surgical intervention will be supported by sufficient sleep quality. Therefore the high incidence of sleep related problems in postoperative children and adolescents is disadvantageous. As there is an association between pain and the quality of sleep, interventions like an adapted pain management should be discussed. Due to the lack of validation of the interviews and the exploratory study design, these results need to be confirmed in further studies.

\section{Competing interests}

The authors declare that they have no competing interests.

\section{Authors' details}

${ }^{1}$ Institute for Medical Informatics, Statistics and Documentation, Medical University of Graz, Austria. ${ }^{2}$ Department of Anesthesiology and Intensive Care, Medical University of Graz, Austria.

Published: 30 October 2015

\section{References}

1. Finan PH, Goodine BR, Smith MT: The association of sleep and pain: an update and a path forward. J Pain 2013, 14(12):1539-52 Dec.

2. Nascimento DC, Andersen ML, Hipólide DC, Nobrega JN, Tufik S: Pain hypersensitivity induced by paradoxical sleep deprivation is not due to altered binding to brain mu-opioid receptors. Behav Brain Res 2007, 178(2):216-20 Mar 28.

3. Volkow ND, Wang GJ, Telang F, Fowler JS, Logan J, Wong C, Ma J, Pradhan K, Tomasi D, Thanos PK, Ferré S, Jayne M: Sleep deprivation decreases binding of $[11 \mathrm{C}]$ raclopride to dopamine D2/D3 receptors in the human brain. J Neurosci 2008, 28(34):8454-61, Aug 20.

doi:10.1186/2056-5917-1-S1-A7

Cite this article as: Rulfs et al:: Sleep and sleepiness in relation to pain in pediatric surgery patients - an exploratory pilot study. Safety in Health 2015 1(Suppl 1):A7.

\footnotetext{
* Correspondence: LukasRulfs@gmx.de

${ }^{1}$ Institute for Medical Informatics, Statistics and Documentation, Medical

University of Graz, Austria

Full list of author information is available at the end of the article
} 